\title{
Detection of human neutrophil elastase by aptamer affinity capillary electrophoresis coupled with laser-induced fluorescence using specified site fluorescently labeled aptamer
}

\author{
Yunlong Bai ${ }^{1,2} \cdot$ Hailin Wang ${ }^{2,3} \cdot$ Qiang Zhao ${ }^{2,3}$
}

Received: 3 July 2017 /Revised: 2 September 2017 / Accepted: 15 September 2017 / Published online: 29 September 2017

(C) Springer-Verlag GmbH Germany 2017

\begin{abstract}
As a multifunctional serine protease, human neutrophil elastase (HNE) plays critical roles in a variety of physiopathological processes, such as acute lung injury, emphysema, atherosclerosis, and arthritis. The quantification of HNE is important in many applications. In this paper, we report an aptamer affinity capillary electrophoresis coupled with laserinduced fluorescence (CE-LIF) assay for detection of HNE using a tetramethylrhodamine (TMR)-labeled DNA aptamer probe. The affinity complex of HNE and DNA aptamer probe was well separated from the unbound aptamer probe in CE separation based on the difference of electrophoretic mobility. Broad complex peaks appeared due to possible multiple binding. The 45-mer aptamer having TMR labeling on the 40th $\mathrm{T}$ base was used as affinity probe, as larger complex peaks were obtained. We investigated the effects of various metal cations $\left(\mathrm{Na}^{+}, \mathrm{K}^{+}\right.$, and $\left.\mathrm{Mg}^{2+}\right)$ in sample buffer on the binding of $\mathrm{HNE}$ and the aptamer in CE-LIF analysis. The presence of $\mathrm{Na}^{+}, \mathrm{K}^{+}$, or $\mathrm{Mg}^{2+}$ in sample buffer caused a decrease of complex peaks, and $\mathrm{Mg}^{2+}$ showed a larger effect. Under optimized conditions, this aptamer CE-LIF assay enabled the detection of HNE at
\end{abstract}

Electronic supplementary material The online version of this article (https://doi.org/10.1007/s00216-017-0645-7) contains supplementary material, which is available to authorized users.

Qiang Zhao

qiangzhao@rcees.ac.cn

1 Institute of Environmental Science, Shanxi University, Taiyuan, Shanxi 030006, China

2 State Key Laboratory of Environmental Chemistry and Ecotoxicology, Research Center for Eco-Environmental Sciences, Chinese Academy of Sciences, Beijing 100085, China

3 University of Chinese Academy of Sciences, Beijing 100049, China
$0.5 \mathrm{nM}$. This assay showed good specificity and allowed for detection of HNE spiked in diluted human serum sample.

Keywords Human neutrophil elastase $\cdot$ Aptamer $\cdot$ Capillary electrophoresis $\cdot$ Laser-induced fluorescence $\cdot$ Affinity binding $\cdot$ Protein detection

\section{Introduction}

Human neutrophil elastase (HNE), a multifunctional serine protease, is mainly secreted by neutrophils under physiological and pathophysiological conditions [1-3]. The high levels of unregulated HNE disrupt the healthy tissues and lead to a variety of diseases, such as chronic obstructive pulmonary disease, emphysema, acute respiratory distress syndrome, atherosclerosis, acute lung injury, and arthritis [1-6]. HNE is a biomarker or a potential therapeutic target, and highly sensitive and specific detection of HNE is in demand. By far, common methods for HNE detection include immunoassays, enzyme activity assay, etc. [7-12].

Aptamers, the single-stranded DNA or RNA oligonucleotides selected by in vitro systematic evolution of ligands by exponential enrichments $[13,14]$, have been used as affinity ligands in sensor designs and assay developments for different targets [15-19]. Compared with antibodies, aptamers have promising features, such as good stability, easy labeling with functional groups, facile production, remarkable specificity, and great affinity for targets [15-19]. Aptamers against HNE have been selected [20-23]. One 45-nt DNA aptamer (5'-TAG CGA TAC TGC GTG GGT TGG GGC GGG TAG GGC CAG CAG TCT CGT-3', denoted ELA45 here) specifically binds to $\mathrm{HNE}$ with a dissociation constant $\left(K_{\mathrm{d}}\right)$ around $17 \mathrm{nM}$ $[22,23]$. A few aptamer-based assays for HNE have been developed, such as fluorescence aptasensor based on 
competitive-binding, affinity capture-based enzyme assay, and luminescent aptamer switch assay [24-26].

Capillary electrophoresis coupled with laser-induced fluorescence (CE-LIF) is rapid and sensitive, requiring low volume of sample and having strength in efficient separation [27-29]. The attractive properties of aptamers, such as highly negatively charged biopolymer, small in size, and ease of labeling with fluorophores [19, 30,31], make aptamer affinity ligand suited for protein detection in affinity CE-LIF. Affinity binding of protein to a dye-labeled aptamer probe changes the electrophoretic mobility of aptamer probe because of the alteration of charge-to-mass ratio, so the aptamer-protein complex can be isolated from the unbound aptamer probe under electric field in CE separation [31]. Aptamer-based CE-LIF assays have been successfully applied to various targets including human immunodeficiency virus type 1 reverse transcriptase, thrombin, immunoglobulin E, platelet-derived growth factor-BB, human erythropoietin-alpha, etc. [30-39].

In this work, we for the first time reported affinity CE-LIF detection of HNE using tetramethylrhodamine (TMR)-labeled DNA aptamer as affinity probe. The HNE-aptamer complexes were well separated from the unbound aptamer probe in CELIF analysis. We conjugated single TMR on different sites of aptamer, including $5^{\prime}$ terminal, $3^{\prime}$ terminal, or the internal $\mathrm{T}$ bases of the anti-HNE aptamer. The aptamer with TMR labeling on the 40th base $\mathrm{T}$ allowed to form large complex peaks. We investigated the effect of cations in sample buffer on the CE-LIF detection of HNE. The high concentration of $\mathrm{K}^{+}$or $\mathrm{Na}^{+}$caused reduction of peak areas of complex peaks, and the addition of $\mathrm{Mg}^{2+}$ significantly decreased the complex peak. Under the optimized conditions, we achieved detection of $0.5 \mathrm{nM}$ HNE. This assay enabled the detection of HNE spiked in diluted human serum samples, showing the capability to detect HNE in complex sample matrix. We also attempted to identify the two complex peaks of HNE and aptamer.
Possibly, the complex peaks corresponded to the complex of one aptamer bound with two HNE molecules and the complex of one aptamer bound with one HNE in CE-LIF analysis.

\section{Experimental}

\section{Materials and reagents}

HNE was ordered from Athens Research \& Technology Inc. (Athens, GA, USA). Thrombin was purchased from Haematologic Technologies Inc. (Essex Junction, VT, USA). Lysozyme, platelet-derived growth factor-BB (PDGF-BB), hemoglobin $(\mathrm{Hb})$, and human immunoglobulin $\mathrm{G}(\mathrm{IgG})$ were ordered from Sigma (St. Louis, MO, USA). Human serum was obtained from Zhongke Chenyu Biotechnology (Beijing, China). Other chemicals of analytical pure grade were obtained from Sinopharm Chemical Reagent Co., Ltd. (Shanghai, China). We prepared all solutions with water $(18.2 \mathrm{M} \Omega \mathrm{cm})$ from Elga Labwater system (Purelab Ultra Genetic, UK). All the DNA oligonucleotides were synthesized and purified by Sangon Biotech (Shanghai, China). Anti-HNE DNA aptamers having single TMR labeling at different positions are listed in Table 1. The schematic structures of the conjugation of TMR and aptamer are shown in Fig. S1 in the Electronic Supplementary Material (ESM).

\section{CE-LIF analysis}

CE-LIF analysis was performed on a laboratory-built system [34-36]. Uncoated fused-silica capillary (Yongnian Company, Hebei, China; $365 \mu \mathrm{m}$ o.d.; $25 \mu \mathrm{m}$ i.d.) with $40 \mathrm{~cm}$ total length (effective length $34 \mathrm{~cm}$ ) was used. The TMR-labeled probes were excited by a 543.5-nm helium-neon laser (Melles Griot, Irvine, CA, USA). The emitted fluorescence was

Table 1 List of DNA aptamers with TMR labeling on various positions

\begin{tabular}{|c|c|}
\hline Name & Sequence \\
\hline ELA45-5'-TMR & 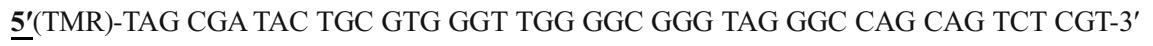 \\
\hline ELA45-T1-TMR & 5'-T(TMR)AG CGA TAC TGC GTG GGT TGG GGC GGG TAG GGC CAG CAG TCT CGT-3' \\
\hline ELA45-T7-TMR & 5'-TAG CGA $\underline{\mathbf{T}}$ (TMR)AC TGC GTG GGT TGG GGC GGG TAG GGC CAG CAG TCT CGT-3' \\
\hline ELA45-T10-TMR & 5'-TAG CGA TAC $\underline{\mathbf{T}}(\mathrm{TMR}) \mathrm{GC}$ GTG GGT TGG GGC GGG TAG GGC CAG CAG TCT CGT-3' \\
\hline ELA45-T14-TMR & 5'-TAG CGA TAC TGC G(TMR)G GGT TGG GGC GGG TAG GGC CAG CAG TCT CGT-3' \\
\hline ELA45-T18-TMR & 5'-TAG CGA TAC TGC GTG GG $\underline{\mathbf{T}}(\mathrm{TMR})$ TGG GGC GGG TAG GGC CAG CAG TCT CGT-3' \\
\hline ELA45-T19-TMR & 5'-TAG CGA TAC TGC GTG GGT $\underline{\mathbf{T}}(\mathrm{TMR}) \mathrm{GG}$ GGC GGG TAG GGC CAG CAG TCT CGT-3' \\
\hline ELA45-T28-TMR & 5'-TAG CGA TAC TGC GTG GGT TGG GGC GGG $\underline{\mathbf{T}}$ (TMR)AG GGC CAG CAG TCT CGT-3' \\
\hline ELA45-T40-TMR & 5'-TAG CGA TAC TGC GTG GGT TGG GGC GGG TAG GGC CAG CAG $\underline{\mathbf{T}}$ (TMR)CT CGT-3' \\
\hline ELA45-T42-TMR & 5'-TAG CGA TAC TGC GTG GGT TGG GGC GGG TAG GGC CAG CAG TCT(TMR) CGT-3' \\
\hline ELA45-T45-TMR & 5'-TAG CGA TAC TGC GTG GGT TGG GGC GGG TAG GGC CAG CAG TCT CGIT(TMR)-3' \\
\hline ELA45-3'-TMR & 5'-TAG CGA TAC TGC GTG GGT TGG GGC GGG TAG GGC CAG CAG TCT CGT-3'-(TMR) \\
\hline
\end{tabular}

TMR labeling position was shown in bold and underline format 
filtered at $575 \mathrm{~nm}$ through a filter (Rochester, NY, USA) and recorded by a photomultiplier tube (PMT, Hamamatsu Photonics, Japan). The signals from PMT were analyzed by a chromatographic software.

TMR labeled aptamer probes (final concentration $10 \mathrm{nM}$ ), varying concentrations of $\mathrm{HNE}$ were incubated in the sample buffer (10 mM Tris-HCl, $\mathrm{pH} 7.5)$ containing a free TMR dye (93 $\mathrm{pM}$, used as an internal standard (IS)) for $1 \mathrm{~h}$ in ice, and then the sample was injected into capillary by applying a positive voltage of $15 \mathrm{kV}$. CE-LIF analysis was performed by applying a voltage of $20 \mathrm{kV}$ at room temperature $\left(25^{\circ} \mathrm{C}\right)$. TG buffer ( $25 \mathrm{mM}$ Tris, $192 \mathrm{mM}$ glycine, $\mathrm{pH} 8.3$ ) was used as separation buffer, which was filtered with $0.22 \mu \mathrm{m}$ filter (Millipore, Bedford, USA). Between each run, the capillary was subsequently rinsed with $20 \mathrm{mM} \mathrm{NaOH}$ for $3 \mathrm{~min}$, water for $2 \mathrm{~min}$, and TG buffer for $2 \mathrm{~min}$, respectively.

\section{Results and discussion}

\section{CE separation of affinity complex}

We tested the feasibility of CE-LIF detection of HNE using TMR-labeled aptamer. The anti-HNE aptamer having TMR labeling at $5^{\prime}$ end (ELA45-5'-TMR) was first used. In CE-LIF analysis, sample was injected into capillary by applying a positive voltage of $15 \mathrm{kV}$ for $5 \mathrm{~s}$, and then CE separation was conducted in TG buffer ( $25 \mathrm{mM}$ Tris, $192 \mathrm{mM}$ glycine, $\mathrm{pH} 8.3$ ) by applying a voltage of $20 \mathrm{kV}$. As Fig. 1 shows, in the absence of HNE, a peak of ELA45-5'-TMR probe appeared at around $1.6 \mathrm{~min}$, and the peak of free TMR dye was observed at about $1 \mathrm{~min}$. When ELA45-5'-TMR (final concentration $10 \mathrm{nM}$ ) was incubated with HNE (final

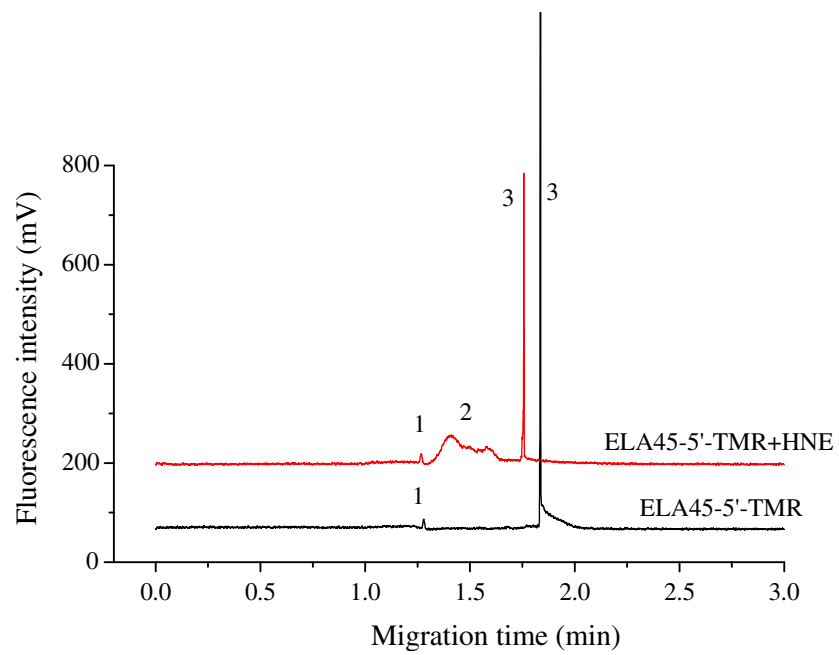

Fig. 1 Electropherograms of ELA45-5'-TMR $(10 \mathrm{nM})$ with and without HNE ( $20 \mathrm{nM})$ present in sample buffer ( $10 \mathrm{mM}$ Tris-HCl, $\mathrm{pH}$ 7.5). Peaks 1,2 , and 3 represent IS, aptamer-HNE complex, and free aptamer, respectively

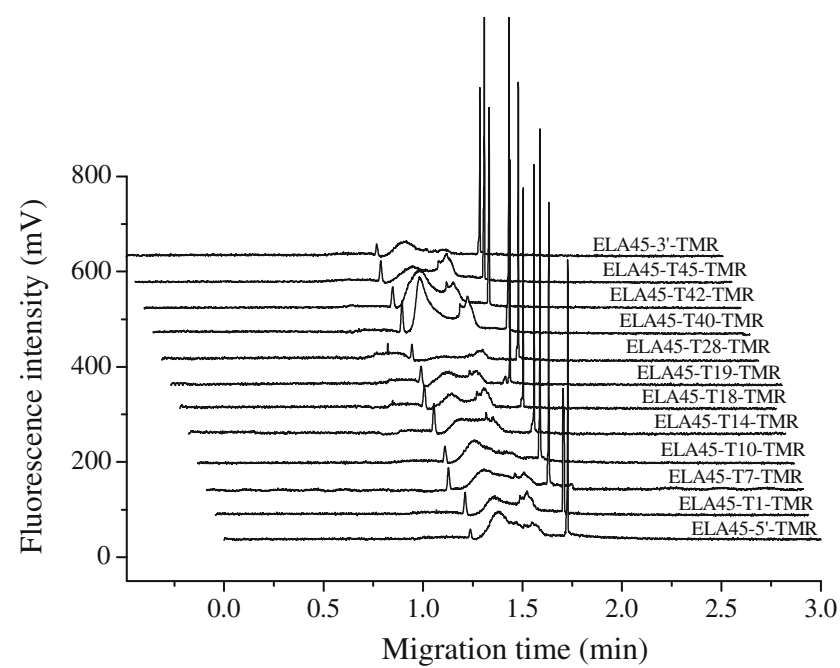

Fig. 2 Electropherograms of aptamer probes with TMR labeling on different positions in the presence of HNE. Aptamer probes $(10 \mathrm{nM})$ were incubated with $\mathrm{HNE}(20 \mathrm{nM})$ in sample buffer $(10 \mathrm{mM}$ Tris- $\mathrm{HCl}$, $\mathrm{pH} 7.5)$

concentration $20 \mathrm{nM}$ ) in sample buffer containing $10 \mathrm{mM}$ Tris- $\mathrm{HCl}(\mathrm{pH} 7.5)$ and injected into capillary, the peak of free ELA45-5'-TMR probe significantly decreased, and a new broad peak appeared at migration time between 1.3 and $1.6 \mathrm{~min}$, which corresponded to the complex of ELA45-5' TMR and HNE (Fig. 1). The result shows that a stable complex is formed during CE separation and it is feasible to develop affinity CE-LIF assay to analyze HNE by using TMRlabeled aptamer.

We further compared the performances of aptamer probes having TMR labeling on different sites of the aptamer in CELIF analysis of HNE, including the $3^{\prime}$ end, $5^{\prime}$ end, and the internal thymine (T) of the aptamer (Fig. S1 in ESM). Totally, 12 different TMR-labeled aptamer probes were obtained (Table 1). For all of the TMR-labeled aptamer probes, broad complex peaks appeared (Fig. 2). Possibly, multiple binding occurred, leading to two complex peaks that were not baseline separated. The complex peaks were well isolated from the peak of the unbound aptamer probe. The peak area of complex peaks of ELA45-T40-TMR and HNE is larger than that obtained by the other TMR-labeled aptamer probes. We chose the ELA45-T40-TMR probe as affinity probe for further work in CE-LIF analysis.

\section{Effect of metal ions in sample buffer}

To obtain better assay sensitivity, we investigated the possible effect of $\mathrm{NaCl}, \mathrm{KCl}$, or $\mathrm{MgCl}_{2}$ in sample buffer $(10 \mathrm{mM}$ Tris$\mathrm{HCl}, \mathrm{pH}$ 7.5) on the separation and detection of HNE in CELIF using ELA45-T40-TMR as probe. As shown in Fig. 3, when $1 \mathrm{mM} \mathrm{NaCl}$ was used in sample buffer, the complex peak increased slightly, and further addition of $\mathrm{NaCl}$ decreased the complex peak area. The same tendency was 
A

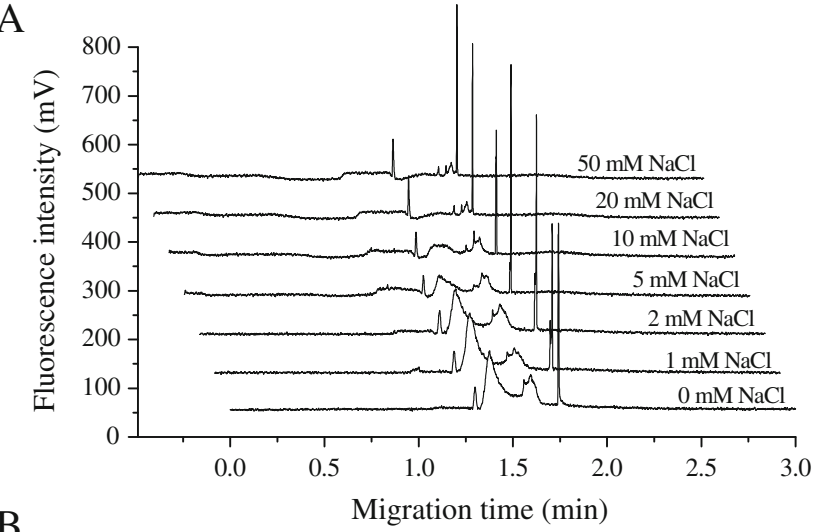

B

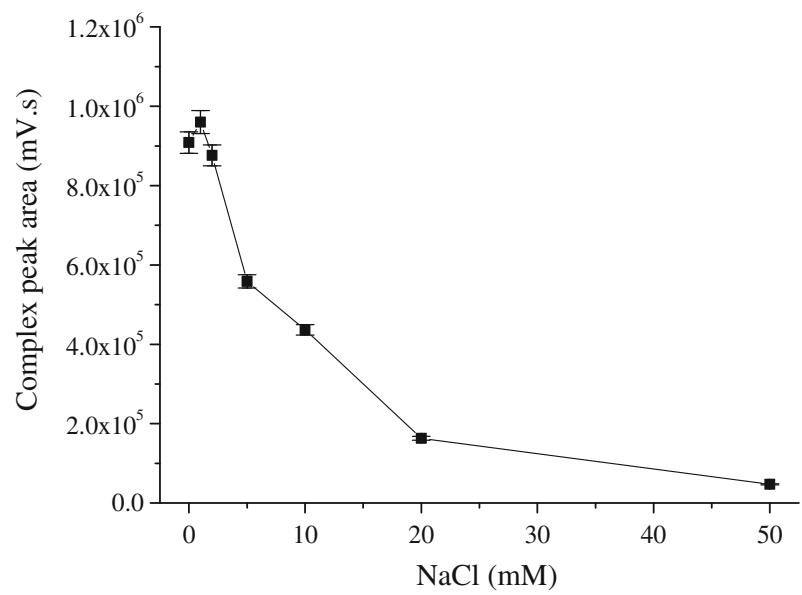

Fig. 3 Effects of $\mathrm{NaCl}$ in sample buffer on CE-LIF analysis of HNE. HNE $(20 \mathrm{nM})$ and ELA45-T40-TMR $(10 \mathrm{nM})$ were incubated in sample solution (10 mM Tris-HCl, $\mathrm{pH} 7.5$ ) containing varying concentrations of $\mathrm{NaCl}$. a Electropherograms corresponding to different concentrations of $\mathrm{NaCl}$. b Relationship between the complex peak area and the concentration of $\mathrm{NaCl}$

observed with the addition of different concentrations of $\mathrm{KCl}$ in the sample buffer (data not shown). The results indicate that $\mathrm{K}^{+}$and $\mathrm{Na}^{+}$at concentrations lower than $2 \mathrm{mM}$ have little effect in CE-LIF analysis of HNE with ELA45-T40-TMR. When the concentration of $\mathrm{KCl}$ or $\mathrm{NaCl}$ was higher than $2 \mathrm{mM}$, the complex peak decreased with the increase of $\mathrm{NaCl}$ or $\mathrm{KCl}$. The complex peak area significantly decreased when $\mathrm{MgCl}_{2}$ as low as $1 \mathrm{mM}$ was present in the sample buffer (Fig. S2 in ESM). The result shows that $\mathrm{Mg}^{2+}$ in sample buffer has more influence on CE-LIF analysis of HNE. The presence of $\mathrm{NaCl}, \mathrm{KCl}$, or $\mathrm{MgCl}_{2}$ in sample buffer may affect the binding between HNE and aptamer in CE-LIF analysis as high concentrations of metal ions may reduce the electrostatic interactions between aptamer and protein and influence the structure of aptamers. Another possible reason is that $\mathrm{NaCl}$, $\mathrm{KCl}$, or $\mathrm{MgCl}_{2}$ may influence the $\mathrm{CE}$ separation. However, the detailed reason is not known. Therefore, we chose to use the sample buffer (10 mM Tris-HCl, $\mathrm{pH} 7.5$ ) without containing $\mathrm{NaCl}, \mathrm{KCl}$, or $\mathrm{MgCl}_{2}$ in the further work.

\section{Quantification of HNE}

Under the optimized condition, we successfully detected varying concentrations of HNE with CE-LIF using ELA45-T40TMR as affinity probe (Fig. 4). With increasing concentrations of HNE, the peak area of complex peaks increased, and the peak area of the peak of unbound aptamer decreased. The complex peak at around 1.5 min first appeared and increased with the addition of HNE. With further increase of HNE (higher than $10 \mathrm{nM}$ ), the complex peak at $1.5 \mathrm{~min}$ began to decrease and another complex peak at about $1.3 \mathrm{~min}$ appeared and increased. The total peak area of two complex peaks was used for quantification of HNE in CE-LIF analysis. The total area of two complex peaks showed linear relationship toward the concentration of HNE in the range from 0.5 to $10 \mathrm{nM}$ $\left(y=88,239 x, R^{2}=0.998\right)$ (Fig. 4b). The narrow linear detection range is related with the concentration of TMR-labeled aptamer $(10 \mathrm{nM})$. When a higher concentration of TMRlabeled aptamer is used, it can be expected that the linear

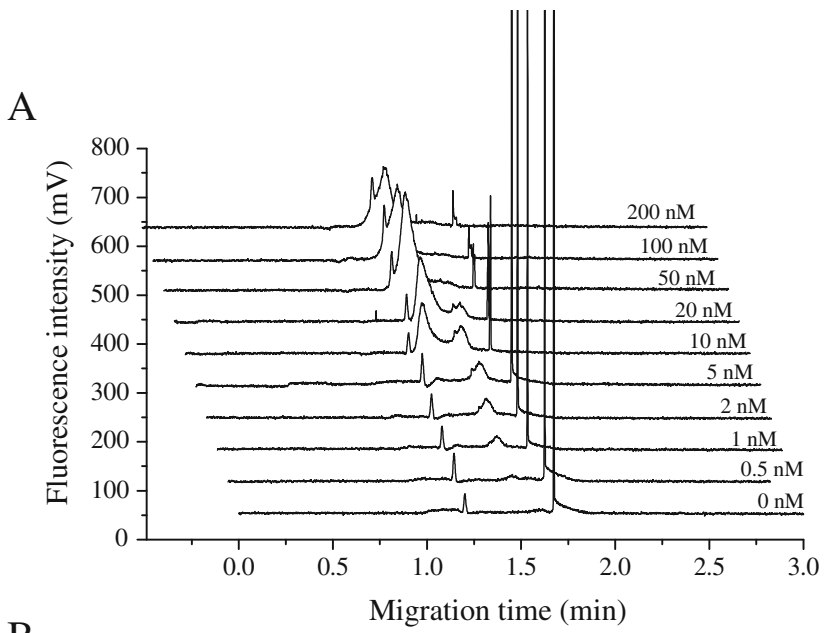

B

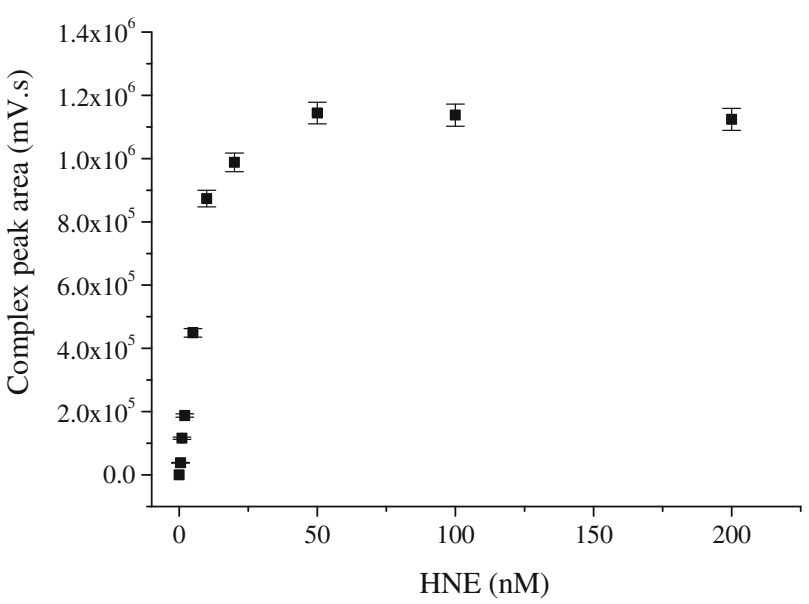

Fig. 4 CE-LIF detection of varying concentrations of HNE by ELA45T40-TMR. a Electropherograms corresponding to varying concentrations of HNE. The corresponding concentration of HNE was indicated at traces. b Relationship between the total peak area of the complex peaks and the concentration of HNE 
detection range for HNE detection will be extended. In addition, the binding affinity of aptamer probes may also affect the detection range as the reported $K_{\mathrm{d}}$ of the aptamer is around $17 \mathrm{nM}[23]$. The detection limit of HNE was $0.5 \mathrm{nM}(S / N=3)$. In this CE-LIF system, the detection limit of the aptamer probe was about $0.1 \mathrm{nM}$, and the linear detection range of the aptamer probe was from 0.1 to $100 \mathrm{nM}$. The obtained complex peak area reached a plateau level when the concentration of HNE was at $50 \mathrm{nM}$. The sensitivity of CE-LIF analysis of HNE in this work is comparable to or higher than aptamer CE-LIF assays for other protein targets [30-35, 37, 38].

\section{Specificity test}

We examined the selectivity of CE-LIF analysis of HNE using ELA45-T40-TMR (10 $\mathrm{nM})$ by testing other proteins $(20 \mathrm{nM})$ including $\mathrm{IgG}, \mathrm{Hb}$, lysozyme, PDGF-BB, and thrombin, and no remarkable complex peak was observed, so these tested proteins did not interfere with the detection of HNE (Fig. S3 in ESM). This result shows that our CE-LIF assay for HNE has good selectivity.

We further tested the applicability of our CE-LIF assay in a complex sample matrix. HNE was spiked into the 100-fold diluted human serum sample and incubated with ELA45-T40TMR probe. HNE was still successfully detected in the 100fold diluted human serum sample (Fig. S4 in ESM). Detection limit of HNE in diluted serum sample was about $5 \mathrm{nM}$, showing the sample matrix has some effects on the HNE. Some proteins in the sample matrix may influence the binding between HNE and aptamer. It is reported that the HNE levels in plasma or serum samples are associated some disease activity $[40,41]$. The levels of HNE in tumor tissues are related with cancer progression [3]. The levels of HNE in serum sample in normal persons are below $100 \mathrm{ng} / \mathrm{mL}(\sim 3 \mathrm{nM})$ [41]. Our method cannot meet the requirement of HNE detection in real plasma or serum samples. More efforts are needed to improve the sensitivity of the assay and the performance of the assay in the complex sample matrix. Our study will be helpful for some research about detection of HNE around nanomolar levels.

\section{Interaction of HNE with aptamer ELA45-T40-TMR}

We attempted to identify the two complex peaks of HNE and aptamer probe in CE-LIF. Figure 5 shows a series of electropherograms for CE-LIF analysis of HNE at a fixed concentration $(20 \mathrm{nM})$ and varying concentrations of ELA45-T40-TMR $(0-100 \mathrm{nM})$. When ELA45-T40-TMR was not present, only the peak of free TMR dye (IS) appeared in the electropherogram. At low concentrations of the aptamer probe (1 and $2 \mathrm{nM}$ ), one main complex peak around 1.3 min was observed in the electropherogram. When the aptamer probe concentration was higher $(5-100 \mathrm{nM})$, another complex peak appeared at about $1.5 \mathrm{~min}$, and this complex peak increased with the

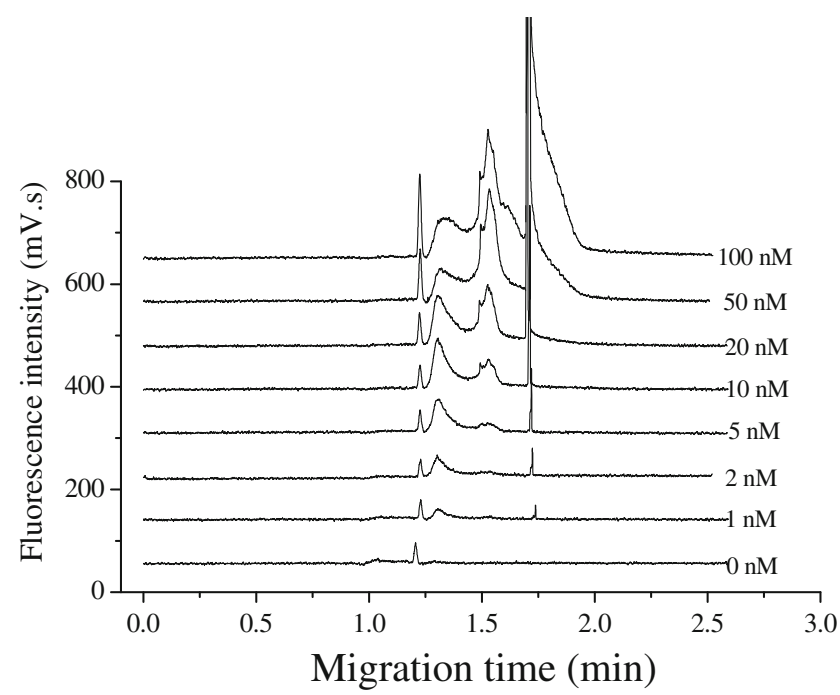

Fig. 5 Electropherograms of HNE $(20 \mathrm{nM})$ incubated with increasing concentrations of ELA45-T40-TMR in sample buffer. From the bottom trace to the top trace, the corresponding concentrations of ELA45-T40TMR were $0,1,2,5,10,20,50$, and $100 \mathrm{nM}$, respectively

increase of aptamer probe concentration. The area of the complex peak at around 1.3 min reached a maximum level when the ELA45-T40-TMR probe concentration was $20 \mathrm{nM}$, and then decreased as the ELA45-T40-TMR concentration further increased. Combining the result shown in Fig. 4, possibly the complex peak at around $1.3 \mathrm{~min}$ represents one ELA45-T40TMR probe binding to two HNE molecules, and the other complex peak at around 1.5 min represents one ELA45-T40TMR probe binding with one HNE molecule. When $20 \mathrm{nM}$ HNE was incubated with low concentrations of aptamer probe, the amount of HNE is excessive, so one aptamer probe may bind more HNE molecules. When $20 \mathrm{nM} H \mathrm{HNE}$ was incubated with high concentrations of aptamer probe, the amount of HNE is relatively not enough for the aptamer probe, so the aptamer probe can only bind with one HNE. The complex of one HNE and one aptamer has larger negative charges to mass ratio than the complex of two HNE and one aptamer, so its migration time is closer to that of the unbound probe.

To further explain the observed complex peaks of HNE, we did more experiments. An aptamer binding to human thrombin with 29 nucleotides (5'-AGT CCG TGG TAG GGC AGG TTG GGG TGA CT-3') was extended to have a 45-nt length by adding 16 Ts at the $3^{\prime}$ terminal of the aptamer and labeled with TMR at the 5' terminal (Apt29T16-5'-TMR: 5'-TMRAGT CCG TGG TAG GGC AGG TTG GGG TGA CTT TTT TTT TTT TTT TTT-3'). This DNA probe has the same length as ELA45-T40-TMR, and they show close migration time due to the same charge to mass ratio (Fig. S5 in ESM) [32]. It has been known that this anti-thrombin aptamer binds to thrombin with a ratio of $1: 1[32,33,35]$. Thrombin has a molecular weight about $36.7 \mathrm{kDa}$. HNE has a molecular weight about $29.5 \mathrm{kDa}$. Figure S5 in ESM shows that the 
complex of thrombin and Apt29T16-5'-TMR has similar migration time with the second complex peak of HNE and ELA45-T40-TMR at around $1.5 \mathrm{~min}$. Considering the same length of DNA probe sequence and close molecular size of thrombin and HNE, the result may further support that the second complex peak of HNE and ELA45-T40-TMR at about $1.5 \mathrm{~min}$ is corresponding to one ELA45-T40-TMR binding with one HNE. The first complex peak of HNE and ELA45T40-TMR at around $1.3 \mathrm{~min}$ was possibly attributed to two HNE binding to one ELA45-T40-TMR as it appeared earlier. However, the exact stoichiometry of the complex peaks of HNE and its aptamer in CE-LIF remains unknown, and other techniques may help to identify the complexes.

\section{Conclusion}

In this work, we reported a specific and sensitive detection of HNE in affinity CE-LIF by using dye-labeled aptamer probe. We conjugated single TMR on $3^{\prime}$ end, $5^{\prime}$ end, or the internal T nucleotide of aptamer. Aptamer having TMR labeling on the 40th $\mathrm{T}$ base was applied to CE-LIF detection of HNE. Two complex peaks appeared in CE-LIF analysis, and they were well separated from the peak of the unbound aptamer. The total area of the complex peaks was applied for quantification of HNE. HNE as low as $0.5 \mathrm{nM}$ was detected. HNE spiked in diluted serum was also detected with CE-LIF analysis. The complex peaks possibly corresponded to the complex of one aptamer binding with two HNE and the complex of one aptamer binding with one HNE, respectively. This work is helpful for the analysis of HNE using aptamer probes.

Funding information This work is supported by the National Natural Science Foundation of China (Grant Nos. 21575153, 21435008) and the Strategic Priority Research Program of the Chinese Academy of Sciences (XDB14030200).

\section{Compliance with ethical standards}

Conflict of interest The authors declare that they have no conflict of interest.

\section{References}

1. Nussbaum FV, Li VM. Neutrophil elastase inhibitors for the treatment of (cardio) pulmonary diseases: into clinical testing with preadaptive pharmacophores. Bioorg Med Chem Lett. 2015;25:437081.

2. Korkmaz B, Horwitz MS, Jenne DE, Gauthier F. Neutrophil elastase, proteinase 3 , and cathepsin $\mathrm{G}$ as therapeutic targets in human diseases. Pharmacol Rev. 2010;62:726-59.

3. Sato $\mathrm{T}$, Takahashi S, Mizumoto $\mathrm{T}$, Harao M, Akizuki M, Takasugi M, et al. Neutrophil elastase and cancer. Surg Oncol. 2006;15:217-22.
4. Pham CT. Neutrophil serine proteases: specific regulators of inflammation. Nat Rev Immunol. 2006;6:541-50.

5. Meyer-Hoffert U, Wiedow O. Neutrophil serine proteases: mediators of innate immune responses. Curr Opin Hematol. 2011;18:19 24.

6. Heutinck KM, ten Berge IJ, Hack CE, Hamanna J, Rowshani AT. Serine proteases of the human immune system in health and disease. Mol Immunol. 2010;47:1943-55.

7. Ferreira AV, Perelshtein I, Perkas N, Gedanken A, Cunha J, Cavaco-Paulo A. Detection of human neutrophil elastase (HNE) on wound dressings as marker of inflammation. Appl Microbiol Biotechnol. 2016;101:1443-54.

8. Castillo MJ, Nakajima K, Zimmerman J, Powers JC. Sensitive substrates for human leukocyte and porcine pancreatic elastase: a study of the merits of various chromophoric and fluorogenic leaving groups in assays for serine proteases. Anal Biochem. 1979;99:5364.

9. Dunn TL, Blackburn WD, Koopman WJ, Heck LW. Solid-phase radioimmunoassay for human neutrophil elastase: a sensitive method for determining secreted and cell-associated enzyme. Anal Biochem. 1985;150:18-25.

10. Herrmann JM, Gonzales JR, Boedeker RH, Vonholdt J, Meyle J. Microassay for the detection of elastase activity in the gingival crevice. J Clin Peridontol. 2001;28:31-7.

11. Kamarun D, Zheng X, Milanesi L, Hunter CA, Krausec S. A peptide cross-linked polyacrylamide hydrogel for the detection of human neutrophil elastase. Electrochim Acta. 2009;54:4985-90.

12. Pouyade GR, Franck T, Salciccia A, Deby-Dupont G, Grulke S, Heyden LV, et al. Development of an enzymelinked immunosorbent assay for equine neutrophil elastase measurement in blood: preliminary application to colic cases. Vet Immunol Immunopathol. 2010;135:282-8.

13. Ellington AD, Szostak JW. In vitro selection of RNA molecules that bind specific ligands. Nature. 1990;346:818-22.

14. Tuerk C, Gold L. Systematic evolution of ligands by exponential enrichment: RNA ligands to bacteriophage T4 DNA polymerase. Science. 1990;249:505-10.

15. Zhou JH, Rossi J. Aptamers as targeted therapeutics: current potential and challenges. Nat Rev Drug Discov. 2016;16:181.

16. Deng N, Liang Z, Liang Y, Sui Z, Zhang L, Wu Q, et al. Aptamer modified organic-inorganic hybrid silica monolithic capillary columns for highly selective recognition of thrombin. Anal Chem. 2012;84:10186-90.

17. Zhao M, Wu T, Xiao X, Liu Y, Su X. New advances in molecular recognition based on biomolecular scaffolds. Anal Bioanal Chem. 2013;405:5679-85.

18. Zhou J, Battig MR, Wang Y. Aptamer-based molecular recognition for biosensor development. Anal Bioanal Chem. 2010;398:247180.

19. Li F, Zhang HQ, Wang ZX, Newbigging AM, Reid MS, Li X-F, et al. Aptamers facilitating amplified detection of biomolecules. Anal Chem. 2015;87:274-92.

20. Charlton J, Kirschenheuter GP, Smith D. Highly potent irreversible inhibitors of neutrophil elastase generated by selection from a randomized DNA-valine phosphonate library. Biochemistry. 1997;36: 3018-26.

21. Charlton J, Sennello J, Smith D. In vivo imaging of inflammation using an aptamer inhibitor of human neutrophil elastase. Chem Biol. 1997;4:809-16.

22. Davis KA, Abrams B, Lin Y, Jayasena SD. Use of a high affinity DNA ligand in flow cytometry. Nucleic Acids Res. 1996;24:702-6.

23. Lin Y, Padmapriya A, Mordent KM, Jayasena SD. Peptide conjugation to an in vitro-selected DNA ligand improves enzyme inhibition. Proc Natl Acad Sci U S A. 1995;92:11044-8. 
24. He JL, Wu ZS, Zhang SB, Shen GL, Yu RQ. Fluorescence aptasensor based on competitive-binding for human neutrophil elastase detection. Talanta. 2010;80:1264-8.

25. Cheng L, Zhao Q. Aptamer-capture based assays for human neutrophil elastase. Talanta. 2013;106:315-20.

26. Leung KH, He HZ, Ma VP, Yang H, Chan DS, Leung CH, et al. A G-quadruplex-selective luminescent switch-on probe for the detection of sub-nanomolar human neutrophil elastase. RSC Adv. 2013;3:1656-9.

27. $\mathrm{Hu}$ S, Dovichi NJ. Capillary electrophoresis for the analysis of biopolymers. Anal Chem. 2002;74:2833-50.

28. Albishri HM, Deeb SE, AlGarabli N, AlAstal R, Alhazmi HA, Nachbar M, et al. Recent advances in affinity capillary electrophoresis for binding studies. Bioanalysis. 2014;6:3369-92.

29. Harstad RK, Johnson AC, Weisenberger MM, Bowser MT. Capillary electrophoresis. Anal Chem. 2016;88:299-319.

30. German I, Buchanan DD, Kennedy RT. Aptamers as ligands in affinity probe capillary electrophoresis. Anal Chem. 1998;70: 4540-5.

31. Pavski V, Le XC. Detection of human immunodeficiency virus type 1 reverse transcriptase using aptamers as probes in affinity capillary electrophoresis. Anal Chem. 2001;73:6070-6.

32. Zhang HQ, Li X-F, Le XC. Tunable aptamer capillary electrophoresis and its application to protein analysis. J Am Chem Soc. 2008;130:34-5.

33. Li YL, Guo L, Zhang FC, Zhang ZY, Tang JJ, Xie JW. Highsensitive determination of human $\alpha$-thrombin by its 29 -mer aptamer in affinity probe capillary electrophoresis. Electrophoresis. 2008;29:2570-7.
34. Hao LH, Bai YL, Wang HL, Zhao Q. Affinity capillary electrophoresis with laser induced fluorescence detection for thrombin analysis using nuclease-resistant RNA aptamers. J Chromatogr A. 2016;1476:124-9.

35. Song MY, Zhang YX, Li T, Wang ZX, Yin JF, Wang HL. Highly sensitive detection of human thrombin in serum by affinity capillary electrophoresis laser-induced fluorescence polarization using aptamers as probes. J Chromatogr A. 2009;1216:873-8.

36. Zhang DP, Lu ML, Wang HL. Fluorescence anisotropy analysis for mapping aptamer-protein interaction at the single nucleotide level. J Am Chem Soc. 2011;133:9188-91.

37. Zhang HQ, Li X-F, Le XC. Differentiation and detection of PDGF isomers and their receptors by tunable aptamer capillary electrophoresis. Anal Chem. 2009;81:7795-800.

38. Shen R, Guo L, Zhang ZZ, Meng QW, Xie JW. Highly sensitive determination of recombinant human erythropoietin-alpha in aptamer-based affinity probe capillary electrophoresis with laserinduced fluorescence detection. J Chromatogr A. 2010;1217: 5635-41.

39. Deng QP, Tie C, Zhou YL, Zhang XX. Cocaine detection by structure-switch aptamer-based capillary zone electrophoresis. Electrophoresis. 2012;33:1465-70.

40. Mikes B, Sinkovits G, Farkas P, Csuka D, Schlammadinger Á, Rázsó K, et al. Elevated plasma neutrophil elastase concentration is associated with disease activity in patients with thrombotic thrombocytopenic purpura. Thromb Res. 2014;133:616-21.

41. Sun G, Ota C, Kitaoka S, Chiba Y, Takayanagi M, Kitamura T, et al. Elevated serum levels of neutrophil elastase in patients with influenza virus-associated encephalopathy. J Neurol Sci. 2015;349:190-5. 